\title{
Armazenamento de grãos na agricultura familiar: principais problemáticas e formas de armazenamento na região nordeste paraense
}

\author{
Grain storage in family agriculture: main problems and ways of storage in the northeast paraense
} region

Almacenamiento de granos en la agricultura familiar: principales problemas y formas de almacenamiento en la región nororiental de paraense

\section{Resumo}

A etapa de armazenamento é tida como uma das fases mais importantes e indispensáveis dentro das etapas de póscolheita de grãos e sementes. $\mathrm{O}$ armazenamento inadequado e a aparição de agentes patogênicos afetam diretamente a sanidade e durabilidade dos grãos ocasionando percas expressivas na produtividade. Diante disso, o trabalho teve como objetivo analisar as principais formas de armazenamento e embalagens utilizadas pelos agricultores familiares e as principais dificuldades enfrentadas na região nordeste paraense. Os principais grãos produzidos pelos agricultores familiares são feijão, milho, arroz e o café, cultura essas que têm grande expressão cultural e econômica, tendo em vista que todos esses compõem como base na alimentação humana e também na alimentação animal. $O$ armazenamento nas propriedades rurais é de grande importância, visto que traz muitos benefícios ao produtor, como, comercialização com maiores lucros, visto que pode ser armazenado e vendido nos períodos de menor oferta, redução de perdas pós-colheita devido ataque de pragas, doenças e mudanças na temperatura e umidade. Apesar da prática de armazenamento ser de extrema importância, grande parte dos produtores rurais ainda utilizam técnicas rudimentares e estruturas improvisadas, que normalmente são inadequadas para o correto acondicionamento dos grãos.

Palavras-chave: Sementes; Pós-colheita; Embalagens; Acondicionamento dos grãos.

\begin{abstract}
The storage stage is seen as one of the most important and indispensable stages within the post-harvest stages of grains and seeds. Inadequate storage and the appearance of pathogenic agents directly affect the health and durability of the grains, causing significant losses in productivity. Therefore, the work aimed to analyze the main forms of storage and packaging used by family farmers and the main difficulties faced by them in the northeast region of Pará. The main grains produced by family farmers are beans, corn, rice and coffee, a culture that has great cultural and economic expression, considering that all of these compose as a basis for human and animal feed. Storage in rural properties is of great importance, since it brings many benefits to the producer, such as marketing with higher profits, since it can be stored and sold in periods of lower supply, reducing post-harvest losses due to pest attacks, diseases
\end{abstract}


and changes in temperature and humidity. Despite the practice of storage being extremely important, most rural producers still use rudimentary techniques and improvised structures, which are usually unsuitable for the correct conditioning of the grains.

Keywords: Seeds; Post-harvest; Packaging; Grain packaging.

\section{Resumen}

La etapa de almacenamiento se considera una de las etapas más importantes e indispensables dentro de las etapas de poscosecha de granos y semillas. El almacenamiento inadecuado y la aparición de agentes patógenos afectan directamente la sanidad y durabilidad de los granos, provocando importantes pérdidas de productividad. Por tanto, el trabajo tuvo como objetivo analizar las principales formas de almacenamiento y envasado que utilizan los agricultores familiares y las principales dificultades que enfrenta la región nororiental de Pará. Los principales granos que producen los agricultores familiares son el frijol, el maíz, el arroz y el café, cultura que tiene una gran expresión cultural y económica, considerando que todos ellos componen como base para la alimentación humana y animal. El almacenamiento en propiedades rurales es de gran importancia, ya que trae muchos beneficios al productor, como la comercialización con mayores ganancias, ya que se puede almacenar y vender en períodos de menor oferta, reduciendo pérdidas poscosecha por ataques de plagas, enfermedades. y cambios de temperatura y humedad. Si bien la práctica de almacenamiento es sumamente importante, la mayoría de los productores rurales aún utilizan técnicas rudimentarias y estructuras improvisadas, que suelen ser inadecuadas para el correcto acondicionamiento de los granos.

Palabras clave: Semillas; Postcosecha; Embalajes; Acondicionamiento de granos.

\section{Introdução}

É sabido que na pós-colheita de grãos e sementes, a fase do armazenamento é vista como uma das etapas mais importantes e indispensáveis. O armazenamento inadequado e a aparição de agentes patogênicos afetam diretamente a sanidade e durabilidade dos grãos e sementes, desta maneira a confiabilidade do mercado com os grãos brasileiros são questionados, afetando diretamente a comercialização dos produtos, ocasionando perdas financeiras significativas (Lorini, 2015).

Seguindo o pensamento do mesmo autor, observando que o armazenamento é visto como uma das etapas do beneficiamento, um dentre os maiores problemas na armazenagem são relacionados a umidade, pragas e doenças, que influenciam na qualidade, peso das sementes e grãos, como também no seu poder germinativo. Um dos princípios do armazenamento de alimentos consiste em controlar a deterioração, que é um processo natural e que causa a modificação física e prejudica a capacidade fisiológica (Oliveira et al., 2012).

Entretanto, a atividade de armazenamento nem toda vez é bem-sucedida, visto que, fatores físicos e biológicos podem interferir na qualidade dos grãos. Como exemplo desses fatores, temos a ação biológica de microrganismos, insetos, fungos, etc., quanto às ações físicas, podem-se citar a temperatura e umidade (Lorini \& Beckel, 2002).

Devido fatores abióticos e bióticos, o armazenamento de grãos é considerado uma atividade arriscada, no decorrer dos anos essa prática vem sofrendo com grandes perdas, podendo chegar a 10\% da produção total (Lorini, 2015). É perceptível também, que o esforço de pesquisas e desenvolvimento tecnológico na agricultura é estritamente direcionado pela necessidade de reverter os efeitos dos desequilíbrios ecológicos sobre os rendimentos, que ocasionam perdas econômicas (Romeiro, 1987).

Determinadas condições ambientais de temperatura, como umidade relativa do ar influenciam na conservação e manutenção da sanidade das sementes durante o período de armazenamento (Carvalho \& Nakagawa, 2000; Warham, 1986). É sabido também, que a longevidade das sementes que são armazenadas é influenciada pelo tipo de embalagem utilizada para o seu acondicionamento (Popinigis, 1985).

A temperatura, umidade, pragas e doenças são os principais fatores responsáveis pealas perdas econômicas significativas na produção, dessa forma, faz-se necessárias novas práticas de armazenamento de grãos capazes de inibir e proporcionar condições favoráveis para a durabilidade do mesmo, tendo em vista que a comercialização de produtos agrícolas está diretamente relacionada às condições de produção e qualidade do produto (Lorini, 2015). 
Com base nesse contexto, observa-se relevância em pesquisas que somem na atribuição de material de literatura com enfoque para o armazenamento de grãos na agricultura familiar da região nordeste paraense, visto que são destacadas a falta de informações no campo, assistência técnica e extensão rural e incentivos governamentais, conforme dados de pesquisas locais (Lima et al., 2018; Silva et al., 2019; Silva et al., 2019; Silva et al., 2020; Rodrigues et al., 2020; Lima et al., 2020; Ferreita et al., 2020;).

Diante disso, o trabalho teve como objetivo analisar as principais formas de armazenamento e embalagens utilizadas pelos agricultores familiares e as principais dificuldades enfrentadas pelos mesmos na região nordeste paraense.

\section{Metodologia}

Para obtenção das informações importantes ao objetivo da pesquisa, o método utilizado foi de revisão bibliográfica, realizando um compilado sobre as principais abordagens teóricas metodológicas publicadas referente ao sistema de armazenamento de grãos, com destaque para as discussões nos contextos da agricultura familiar e suas principais formas de armazenamento.

A pesquisa bibliográfica foi realizada através dos principais meios de busca de bases de dados eletrônicos científicos, relacionados a práticas de armazenamentos de grãos e as principais culturas trabalhadas dentro da agricultura familiar. A pesquisa foi realizada segundo semestre de 2019 até o início de 2020. As principais bases eletrônicas utilizadas foram o periódico CAPES/MEC, Scientific Eletronic Library Online-Scielo e Google Acadêmico.

A pesquisa é de natureza qualitativa, com metodologia de caráter exploratório, onde teve como principal objetivo destacar com profundidade sobre o tema em estudo e aprofunda-lo para melhor compreensão dos resultados.

Após a coleta das informações, selecionaram-se os que atendiam o objetivo do estudo, não se estabelecendo limite de ano para o material uma vez que as informações presentes na literatura sobre o assunto são escassas.

Os resultados foram organizados de modo estrutural para melhor compreensão dos leitores. Visando mostrar as principais culturas armazenadas pelos produtores rurais, importância, principais forma de armazenamentos, principais embalagens utilizadas, principais problemáticas enfrentadas pelos produtores e algumas medidas preventivas e de controle de pragas.

\section{Revisão Bibliográfica}

\subsection{Principais grãos produzidos pelos agricultores familiares.}

Feijão caupi (Vigna unguiculata (L.) Walp).

O feijão-caupi é uma espécie leguminosa originária da África, é uma dicotiledônea, da ordem Fabales, família Fabaceae. No Brasil é conhecido empiricamente por diversos nomes, como: feijão-de-praia, feijão-da-colônia, feijão-deestrada e feijão-miúdo (Freire Filho, 1988; Freire Filho, Cardoso \& Araújo, 1983; Maréchal, Mascherpa, \& Smartt, 1990; Stainier, 1978).

No Brasil, o feijão-caupí possui grande importância social, cultural e econômica, sendo cultivado para subsistência ou/e comercialização nas regiões Norte e Nordeste do país, essa cultura possui características de rusticidade e precocidade, dessa forma, se adapta bem as adversidades climáticas e edáficas (Dantas et al., 2002).

Com relação a seus aspectos socioeconômicos, o feijão se destaca por ser uma cultura de grande importância para os produtores familiares locais para sua subsistência e também por se geradora de empregos, possuindo grande impacto na renda (Kakade \& Evans, 1965). Apesar do cultivo do feijão-caupí ser realizado, principalmente, pela agricultura familiar, seu cultivo em maior escala, com a utilização de alta tecnologia, já passou a fazer parte do cotidiano da cultura no norte e nordeste do país, como, no estado do Pará (Cravo, Smyth \& Souza, 2006). 
A produção dessa leguminosa concentra-se nas regiões Norte e Nordeste e está se expandindo para o Centro-Oeste, devido sua ampla adaptabilidade às condições tropicais e ao pequeno custo de produção e também possui amplo significado social, cultural e econômico, constituindo-se em um dos mais importantes alimentos proteicos e energéticos produzido pela agricultura familiar (Menezes et al., 2007).

Dados do IBGE (2019), apresenta uma estimativa voltada a produção de feijão em grãos para o ano de 2019 foi de 3.000.000.00 de toneladas. Com relação à safra de 2018, a produção total de feijão deve crescer 1,7\%. Todavia, o feijão-caupi é uma cultivar que ainda apresenta diversas problemáticas, seja devido fatores bióticos ou abióticos, como incidência de doenças e pragas ou umidade excessiva, durante seu ciclo de desenvolvimento ou em condições de estocagem. Destacam-se como as principais pragas de grãos de feijão-caupi a Plodia interpunctella e a Callosobruchus maculatus (Marsaro, 2007).

\section{Milho}

O Brasil possui um grande número de agricultores familiares que fazem o cultivo de milho, muitos destes conduzem lavouras com baixa utilização de insumos e em condições desfavoráveis, tanto do ponto de vista, econômico, político, social e técnico (Agricultura, 2020).

O milho possui grande importância social, cultural e econômica na agricultura familiar e também no agronegócio, que é caracterizada pelas diversas formas de sua utilização, que vai desde a alimentação animal até a indústria de alta tecnologia. O uso deste grão no consumo animal representa grande parte do consumo desse cereal no mundo. No Brasil, varia de 70 a $90 \%$, dependendo da fonte da estimativa e da região geográfica (Cruz et al., 2011). Com relação ao aspecto nutricional, o milho é a fonte de energia para muitas pessoas que vivem no Semiárido (Duarte et al., 2010).

Apesar da maioria das tecnologias utilizadas pelos grandes produtores também possam ser utilizada pelos pequenos produtores, existem diversos fatores que diferenciam a produção da agricultura familiar, como a utilização de alta tecnologia, insumos agrícolas e principalmente a forma de armazenamento, visto que, a maioria das estruturas de armazenamento são precárias e improvisadas (Cruz et al., 2011).

A maioria dos produtores familiares produzem o milho para ser utilizado na propriedade, para sua própria alimentação e também dos animais. Apenas uma pequena parcela da produção é vendida, geralmente o excedente produzido é comercializado pelos agricultores, preferencialmente para o mercado local. Nas pequenas propriedades familiares, o agricultor geralmente espera o milho secar naturalmente no campo e pode realizar a colheita do milho em etapas, colhendo aos poucos a lavoura conforme sua necessidade e disponibilidade (Cruz et al., 2011).

Perdas durante o armazenamento, ocasionado pela presença de insetos, roedores e fungos ainda são bastante frequentes. Calcula-se que no mínimo $15 \%$ das perdas de produtos armazenados é causado diretamente por insetos e fungos (Santos \&Mantovani, 1997; Dalpasquale, 2006; Santos, 2008).

$\mathrm{Na}$ agricultura familiar, o estabelecimento para o armazenamento de milho em espigas apresenta algumas características especiais, como, por exemplo, baixo custo e a durabilidade, uso de materiais que possibilitam o bom arejamento das estruturas, facilidade para o controle de pragas e outras (Santos, 2006, 2008b).

\section{Arroz}

Os novos resultados referentes à agricultura familiar não foram publicados em papel, mas estão disponíveis no site do IBGE. No Brasil, em 2006, a agricultura familiar participou com 33,1\% da produção de arroz em casca (IBGE, 2006).

O arroz está entre os principais cereais cultivados no Brasil, respondendo por cerca de 1,8\% da produção mundial de arroz e por $52 \%$ da produção na América do Sul. As produções de arroz têm crescido gradativamente no decorrer dos anos. 
Parte desse crescimento deve-se ao melhor ambiente em que está se inserindo a cultura, que corresponde a melhorias no manejo do solo, juntamente com a adequada utilização de insumos (Azambuja, 2004).

O arroz é cultivado amplamente em todo território brasileiros e, no ano de 2002, foi cultivado em $70 \%$ dos 5543 municípios do país. Sua renda, importância econômica e social diferem de acordo com as condições agroclimáticas e a tradição da cultura na região (IBGE, 2006).

A produção de arroz teve um crescimento médio anual de 1,67\% nos últimos 13 anos. Parte desse valor foi devido ao aumento dos rendimentos de 4,1\% ao ano. A média da produção nacional passou de 2,084 t/ha no triênio 1989 a 1991 para 3,241 t/ha nos anos 2000-02. Por outro lado, as áreas cresceram, em média, 1,94\% ao ano (IBGE, 2004).

Com relação aos seus aspectos nutricionais, considerando os diversos tipos de arroz e as preparações à base de arroz, verifica-se que fornecem 12,9\% da energia total dos alimentos consumidos. De acordo com o IRGA (2004), o potencial genético de produção das atuais cultivares de arroz se encontra entre 10 e 12 t/ha.

Entretanto, é importante ressaltar que o arroz é atacado por diversas pragas, algumas danificam a produção no campo, outras deterioram os grãos apenas em armazenamento, mas também existem outras que danificam os grãos tanto no campo quanto nos armazéns (Link et al., 1971).

Os grãos de arroz estão sujeitos a perdas na qualidade fisiológica, sanitária e nutricional desde sua maturação fisiológica, no campo, até o momento do consumo, por esse motivo faz-se de extrema importância estudos relacionados as formas de armazenamentos mais adequadas à cultura. Essas alterações citadas são causadas normalmente por fungos, insetos e manuseio inadequado na colheita, recebimento, secagem, armazenamento e/ou processamento do produto, resultando em prejuízos financeiros aos armazenadores e processadores (Lazzari 1997; Lazzari \& Lazzari, 2002).

\section{Café}

O café é um dos produtos agrícolas mais importantes no mundo, visando seus aspectos sociais e econômicos para mais de 60 países produtores, visto que serve tanto para o consumo na agricultura familiar como também para o agronegócio e exportação (OIC, 2012), constituindo-se em uma das cinco potencialidades agrícolas mais comercializadas no mundo (FAO, 2010).

O café sobressai na economia mundial, ocupando a segunda colocação na geração de riqueza do planeta, após o petróleo (Mishra \& Slater, 2012), ocupa posição de destaque na economia mundial, na geração de empregos e renda, tanto para os países produtores como consumidores (Pontes, 2002). Ainda no início do século XXI, o consumo de café no mundo foi estimado em cerca de 2,25 bilhões de xícaras (Davicon \& Ponte, 2005).

As literaturas mostram uma produção mundial em 2014 entre 143,0 e 152,6 milhões de sacas de 60 kg beneficiadas, com valor mais real próximo de 146.000.000.00 de sacas (Carvalho, 2015; OIC, 2015; USDA, 2015). De maneira análoga a Organização Internacional do Café (OIC), diante de um crescimento no consumo de 1,5\% a 2,5\% ao ano, acredita-se que, em 2025, o mundo demandará aproximadamente 25 a 35 milhões de sacas de café a mais (Anuário, 2015).

Com essa crescente demanda que vem aumentando ao longo dos anos, é de suma importância atentar para as condições ideais de secagem e armazenamento de grãos de café, visto que é fundamental para a manutenção da viabilidade das sementes durante esse processo, para tanto, deve-se atentar para o teor de umidade das sementes, embalagem, temperatura e tempo de armazenamento (Vieira et al., 2013).

No Brasil o café é armazenamento tradicionalmente em sacos de juta de $60 \mathrm{~kg}$, que são dispostos em armazéns onde se pratica pouco ou nenhum controle sobre o ambiente. Desse modo, condições ambientais externas podem afetar as condições de umidade e temperatura (Lopes, et al., 2000). Como as sementes de café são muito sensíveis à desidratação, essa tem sido considerado o principal fator da rápida perda do poder germinativo durante o armazenamento (Ellis, Hong \& Robert, 1990). 


\subsection{Importância do armazenamento de grãos para o pequeno agricultor.}

Nos primórdios da humanidade, provavelmente há 10.000 anos, o homem começou a perceber a importância da relação semente-planta, esse fato provocou grande modificações em suas vidas, visto que uma semente posta no solo dava origem a uma planta, e gerava muitas outras sementes. Diante disso, visto a necessidade de proteger seus alimentos de inimigos naturais como, ataque de animais, fatores ambientais como tempestade, plantas daninhas e entre outros, o homem percebeu a necessidade de modificar profundamente seus hábitos, passando da vida nômade para sedentária (Carvalho \& Nakagawa 2000).

Com relação aos tempos atuais, o armazenamento nas propriedades rurais é de suma importância, visto que, se feito de forma adequada, traz muitos benefício ao produtor, como, comercialização com maiores lucros, já que pode ser armazenado e vendido nos períodos de menor oferta, redução de perdas pós-colheita devido ataques de pragas e proliferação de microrganismos, diminuição dos custos relativos a fretes quando se evita transporte em época de grande demanda deste e dentre outros benefícios (Medina, 1989). O autor também afirma que, a ausência de silos ou outras estruturas de armazenamento de grãos, induz a riscos e despesas, que diminuem a rentabilidade do produtor.

A prática de estocagem de grãos nas propriedades familiares é realizada frequentemente utilizando técnicas arcaicas e estruturas improvisadas, inadequadas para o correto armazenamento dos grãos. A maioria dos agricultores cultiva o milho, feijão, arroz, para o próprio consumo dentro da propriedade, e também dos animal (Santos, 2008; Albernaz et al., 2010)

Deve-se iniciar o armazenamento das sementes durante a maturidade fisiológica, tendo como objetivo manter a qualidade dos grãos durante o período de estocagem. Fator esse de extrema importância, visto que a maioria dos agricultores familiares tem o hábito de armazenarem as sementes para propagarem na safra seguinte. (Villela \& Peres, 2004).

Dados divulgados pelo IBGE (2004), mostram que da perda média de grãos armazenados no Brasil está estimada em aproximadamente $10 \%$ do total produzido anualmente, tomando como base a estimativa de 153 milhões de toneladas para a produção na safra 2010/1011 baseado nos dados da CONAB (2011), este percentual pode então representar mais de 15 milhões de toneladas de grãos perdidos. Levando em consideração a perda em qualidade, os valores podem ser ainda maiores, visto que a infestação por pragas compromete o valor comercial dos grãos (Barberato, 2001).

Enquanto os danos causados no campo podem ser compensados pela recuperação da planta danificada ou pelo aumento de produtividade de plantas não atacadas, os prejuízos em grãos armazenados são irrecuperáveis (Fontes et al., 2003).

\subsection{Principais forma de armazenamentos na agricultura familiar.}

\section{A granel}

O armazenamento a granel faz parte de uma tendência adotada em diversas partes do mundo. Basicamente, os depósitos com finalidade de armazenar grãos de forma a granel, são chamados de silos. Os agricultores familiares produtores de grãos utilizam frequentemente silos de médio e pequeno poste, que são metálicos, de alumínio ou ferro. Os silos metálicos herméticos, de média e grande capacidade, que oferecem maior qualidade são mais utilizados pelos grandes produtores. (Puzzi, 2000).

\section{Em sacos}

O armazenamento em sacos, nos armazéns e na propriedade de pequenos produtores é a prática mais utilizada no país. Essa prática, apresenta diversos problemas, tais como: os grãos ficam vulnerável às condições do meio ambiente e lugares de alta umidade, o produto pode ser prejudicado pela ação de fungos e outros fatores. Por outro lado, o armazenamento em sacos apresenta alguns pontos positivos como facilidade na manipulação, formações de lotes de um mesmo depositante, ocorrendo 
fermentações em um ou mais sacos de grãos, os mesmos poderão ser retirados, sem causar mais danos em todo os grãos armazenados (Puzzi, 2000).

\section{Em armazéns}

Os grãos quando armazenados, deverão estar secos e limpos. Os depósitos, nas fazendas destinados a receber os produtos ensacados devem proteger os grãos, principalmente, contra a umidade, água de chuva e infiltração de vapor d'água (Puzzi, 2000).

\subsection{Principais embalagens utilizadas para o armazenamento na agricultura familiar.}

As embalagens das sementes são importantes não apenas para o transporte, armazenamento e comercialização dos grãos, mas também no que se refere à conservação da qualidade das mesmas sob determinadas condições ambientais de temperatura e umidade (Popinigis, 1985).

Segundo Crochemore (1993), as embalagens utilizadas no acondicionamento das sementes durante o armazenamento também assumem relevante importância na manutenção da sua viabilidade e vigor, sementes conservadas em embalagens que permitem trocas de vapor d'água com o ar atmosférico podem absorver água sob alta umidade relativa do ar, deteriorando-se com facilidade.

Pode-se dividir as embalagens em permeáveis, semipermeáveis e impermeáveis, de acordo quanto as trocas de vapor de água em função das trocas de umidade que podem ocorrer entre as sementes e o ambiente em que elas estão (Baudet, 2003).

Quando as sementes são armazenadas em embalagens permeáveis, que são papel, juta, algodão e plástico trançado, seu teor de umidade varia conforme as variações da umidade do ar, devido ao fato das mesmas serem higroscópicas (Baudet, 2003; Popinigis, 1985).

Em embalagens semipermeáveis como, sacos plásticos finos ou de polietileno, de 0,075 a 0,125 mm de espessura, e sacos de papel multifoliado laminados com polietileno, há alguma resistência as trocas, porém não impede a passagem da umidade (Baudet, 2003; Popinigis, 1985).

Em embalagens impermeáveis como, sacos de plástico, com mais de 0,125 mm de espessura selados ao calor, pacotes de alumínio e latas de alumínio, quando bem vedados, a umidade do ar externo não exerce influência sobre as sementes (Baudet, 2003; Popinigis, 1985).

Visto que a atmosfera modificada pode ser obtida com a utilização de filmes de polietileno (ROSSIGNOLI, 1983), dentre os filmes plásticos mais usados, destacam-se os poliolefinicos, como o polietileno, o polipropileno e o polibutileno, assim como seus copolímeros (Penteado,1998).

\subsection{Principais problemáticas enfrentadas pelos produtores.}

De acordo com Santos (2006), um lote de grãos armazenados é um material propicio às transformações, deteriorações e perdas devido a interações entre os fenômenos físicos, químicos e biológicos. Os fatores temperatura, umidade, disponibilidade de oxigênio, microrganismos, insetos, roedores e pássaros exercem grande influência nesse ambiente.

A umidade ocasiona maior perda das sementes, a colheita com alta concentração de água e armazenagem com pouca entrada de ar, são condições que favorecem gradientes de umidade, com consequente proliferação de fungos. Deve-se realizar secagem homogênea para que os grãos tenham uma armazenagem segura, menor que 13\%, mantê-los em ambiente sem roedores e evitar quebra de grãos durante suas etapas de beneficiamento (Jouany, 2007).

De acordo com Popinigis (1977), quanto as sementes são armazenadas com alto teor de água, maior são as chances de fatores adversos prejudicando à conservação de suas qualidades. Os principais fatores que afetam diretamente na qualidade 
fisiológica da semente é a temperatura e a umidade presente no local de armazenamento. Visto que a umidade relativa do ar está diretamente relacionada com o teor de água nas sementes, já a temperatura está relacionada a velocidade dos processos bioquímicos (Popinigis, 1977).

Com relação aos ataques de pragas, que também é um dos principais problemas enfrentado pelos produtores, existem várias espécies de insetos que se alimentam dos grãos, porém o gorgulho e a traça-doscereais, são responsáveis pelas perdas (Santos, 2006).

Os insetos se alimentam dos grãos e provocam grandes perdas, as quais podem ser consideradas sob diferentes aspectos, tais como, perda de peso dos grãos, perda do poder germinativo e do vigor da semente, perda do valor nutritivo, da qualidade e entre outros. (Santos, 2006).

Existem dois grupos de insetos que fazem parte dos principais fatores de perca da produção durante a etapa do armazenamento, que são, os besouros (carunchos) e as traças (mariposas). O gorgulho ou caruncho, são consideradas as principais pragas que atacam os grãos armazenados, sendo responsáveis pela maior parte das perdas (Lorini, 2001, 2002; Faroni \& Sousa, 2006).

Os fungos de armazenamento, como o Aspergillus e o Penicillium, contaminam os grãos após a colheita e têm a capacidade de viver associados a grãos com teor de umidade mais baixo (13 a 13,5\%) e temperaturas mais elevadas (25oC). Os principais fatores que afetam a atividade dos fungos nos grãos armazenados são: umidade, temperatura, taxa de oxigênio, danos mecânicos, impurezas e ataque de insetos. (Santos, 2006).

\subsection{Medidas preventivas e de controle no armazenamento de grãos.}

Uma medida eficiente para evitar pragas no armazenamento é a escolha de embalagens eficientes, visto que são uma barreira física que previne ou impede a infestação por insetos. No entanto, vários insetos, como L. serricorne, Stegobium paniceum (Linnaeus), P. interpunctella, C. cautella, Corcyra cephalonica (Stainton) e Trogoderma variable, são capazes de penetrar até nas embalagens intactas (Faroni \& Silva, 2000).

A principal fonte de umidade para os insetos é a umidade inicial do grão e a umidade atmosférica e a água metabólica. Dessa maneira, deve-se considerar o equilíbrio higroscópico estabelecido entre a umidade atmosférica e a umidade do grão, visto que a umidade e a temperatura são fatores que influenciam a sobrevivência e a reprodução de muitos insetos (Faroni \& Silva, 2000).

De acordo com o mesmo autor, a eficácia de um método de controle de insetos em grãos armazenados depende da estimativa precisa da densidade populacional de insetos. Desse modo, com relação as formas mecânicas de controle de insetos em produtos armazenados, são conhecidos dois os métodos básicos: indireta, que se baseia na manipulação do meio ambiente, e o método direto que é a manipulação dos insetos (Faroni \& Silva, 2000).

Um dos métodos indiretos é a limpeza ou redução de impurezas e matérias estranhas, como, sementes quebradas, terra, pedras e sementes de ervas daninhas e sementes com rachaduras no endosperma. Um método direto de controle é a retirada da população de insetos da área. Os equipamentos utilizados para remover impurezas e matérias estranhas devem também remover insetos que estão fora da semente (Faroni \& Silva, 2000).

Outra forma de controle é o Manejo Integrado de Pragas (MIP) é uma metodologia que usa análises de custo-benefício para a tomada de decisões. Em programas de manejo de pragas, o controle é economicamente eficiente se o custo de controle for menor que a redução no valor de mercado, causada pela praga. A alternativa ao Manejo Integrado de Pragas é o uso de inseticidas em doses regulares, sem determinar se o controle de insetos é necessário (Faroni \& Silva, 2000).

Dessa forma, outro método de controle é químico, que como intuito complementar mais do que suplantar outras medidas, como sanidade, manejo da temperatura e da umidade, uso de instalações adequadas etc. Os produtos químicos são 
frequentemente utilizados no controle de insetos, devido suas facilidades na aplicação e maior rapidez de ação, além de ser, atualmente, um dos métodos mais econômicos. Entretanto, as desvantagens desse método são: o controle não é permanente; há riscos, como explosões, resíduos e toxicidade, no momento da aplicação; e, ainda, a resistência dos insetos e o custo dos inseticidas e equipamentos (Faroni \& Silva, 2000).

\section{Considerações Finais}

Pode-se perceber que a faze do armazenamento é considerado uma das etapas mais importantes quando se refere a qualidade dos grãos.

Os fatores temperatura, umidade, disponibilidade de oxigênio, microrganismos, insetos, roedores e pássaros exercem grande influência nos ambientes de armazenamento, podendo levar até a perda total dos lotes de sementes.

As principais culturas produtoras de grãos plantadas pelos agricultores familiares são milho, feijão, arroz e café, devido ser culturas que podem ser comercializadas e também utilizadas na alimentação da família e dos animais da propriedade.

Apesar da prática de armazenamento ser de extrema importância, a maioria dos produtores rurais ainda utilizam técnicas rudimentares e estruturas improvisadas, que geralmente são inadequadas para o correto acondicionamento dos grãos.

Diante disso, devido as diversas problemáticas nas técnicas de armazenamento na agricultura familiar, sugere-se o desenvolvimento de novas pesquisas que visem descobrir novas técnicas de armazenagem, com enfoque na qualidade e viabilidade para pequenos produtores.

\section{Referências}

Agricultura familiar: linha de pesquisa. http://www.ufv.br/dft/milho/agricultura_familiar.htm

Albernaz, W. M., Cruz, J. C., Pereira Filho, I. A., Matrangolo. W.J. R., Noce. M. A., Chaves. F. F., \& Guimarães Sobrinho. J. B. (2010). Concurso de produtividade de grãos na cultura do milho na região Central de Minas Gerais - Safra 2009/2010. In: congresso nacional de milho e sorgo, 28, Simpósio Brasileiro sobre a lagarta do cartucho, 4, 2010, Goiânia. Potencialidades, desafios e sustentabilidade: resumos expandidos... Goiânia: ABMS, 1 CD-ROM.

Anuário brasileiro do café (2015). Uma conta estreita. In: Carvalho, C. de et al. Gazeta, 26, 2015, 104 p.

Azambuja, I. H. V., Vernettti Junior. F. J. \& Magalhães Junior. A. M. (2004). Aspectos socioeconômicos da produção de arroz. In: Gomes, A. S., \& Magalhães Júnior, A. M. Arroz irrigado no sul do Brasil. Brasília, DF: Embrapa, 23-44.

Barberato, C. L. (2001). Altas perdas.

Baudet, L. M. L. (2003). Armazenamento de sementes. In: Peske, S. T., Rosental, M. D., \& Rota, G. R. (ed.). Sementes: fundamentos científicos e tecnológicos, Pelotas: Ed. Universitária - UFPel, 370-418.

Brasil. (2009). Ministério da Agricultura, Pecuária e Abastecimento. Secretaria de Defesa Agropecuária. Regras para análise de sementes. Brasília. http://www.agricultura.gov.br.

Carvalho, N. M., \&Nakagawa, J. (2000). Sementes: ciência, tecnologia e produção. (4a ed.), FUNEP, 588.

Carvalho, J. (2015). Oferta de arábica no Brasil: Diferença entre as estimativas de produção brasileira. Food \& Agri Research. Rabobank Brasil. Palestra Coffee Dinner 2015. São Paulo, SP.

Conab (2011). Companhia Nacional de Abastecimento. Safra de grãos cresce em área e produção e chega a 153 milhões de toneladas.

Cravo, M. S., Smyth, T. J. \& Souza, B. D. L. (2006). Nível crítico de potássio para o feijão-caupi em Latossolo Amarelo textura média no Nordeste paraense. In: Reunião nacional de feijão-caupí, 6. 2006, Teresina. Anais... Teresina: Embrapa Meio-Norte, 1 CD- ROM.

Crochemore, M. L. (1993). Conservação de sementes de tremoço azul em diferentes embalagens. Revista Brasileira de Sementes, Londrina, 5(2), $227-232$.

Cruz, J. C., Israel Filho, A. P., Pimentel, M. A. G., Coelho, A. M. Karam, D., Cruz, I., \& Matrangolo, W. J. R. (2011). Produção de milho na agricultura familiar. Embrapa: Sete Lagoas, MG. Setembro.

Dalpasquale, V. A. (2006). Post-harvesting corn losses indexes in a storage unit: A case study. In: International Working Conference On Stored-Product Protection, 9. Campinas. Proceedings... Campinas: ABRAPOS, 64-70. 
Dantas, J. P., Marinho, F. J. L., Ferreira, M. M. M., Amorim, M. S. N., Andrade, S. I. O., \& Sales, A. L. (2002). Avaliação de genótipo de caupí sob salinidade. Revista brasileira de Engenharia Agrícola e Ambiental. 6(3), 425-430.

Davicon, B., \& Ponte, S. (2005). The coffee paradox: global markets, commodity trade and the elusive promise of development. Zed Books.

Duarte, J. O., Cruz, J. C., Garcia, J. C. \& Mattoso, M. J. (2010). Economia da produção. In: Cruz, J. C. (Ed.). Cultivo do milho. (6a ed.), Sete Lagoas: Embrapa Milho e Sorgo.

Ellis, R. H., Hong, T. D., \& Roberts, E. H. (1990). An intermediate category of seed storage behaviour? I. 270 Café Conilon - Capítulo 10 Coffee. Journal of Experimental Botany, Oxford, 41(230), 1167-1174.

FAO (2010). Food and Agriculture Organization of the United Nations.

Faroni, L. R. D. A., \& Silva, J. S. (2000). Manejo de pragas nos ecossistemas de grãos armazenados. In: Silva, J. S. Secagem e armazenagem de produtos agrícolas. Viçosa, MG: Universidade Federal de Viçosa.

Ferreira, A. S., Viegas, I. J. M., VIegas, S. F. S. S., Silva, D. A. S., Da Silva, A. O., Demartelaere, A. C. F., \& Preston, H. A. F. (2020). A agricultura familiar da Vila Siquiriba, município de Primavera -PA: Desafios e soluções do início da linha de produção até a comercialização dos produtos. Brazilian Journal of Development, (6), 73518-73533. 10.34117/bjdv6n9-710

Fontes, L. S., Almeida Filho, A. J. \& Arthur, V. (2003). Danos causados por Sitophilus oryzae (Linné, 1763) e Sitophilus zeamais Motschulsky,1855 (Coleóptera: Curculionidae) em Cultivares de Arroz (Oryza sativa L.). Arquivos do Instituto Biológico, São Paulo, 70(3,). 303-307.

Freire Filho, F. R. (1988). Origem, evolução e domesticação do caupi. In: Araújo, J. P. P. De, Watt, E. E. (Org.). O caupí no Brasil. Brasília, DF: IITA: EMBRAPA, 26-46.

Freire Filho, F. R., Cardoso, M. J. \& Araújo, A. G. (1983). Caupi: nomenclatura científica e nomes vulgares. Pesquisa Agropecuária Brasileira, Brasília, DF, 18(12), 1369-1372. http://seer.sct.embrapa.br.

IBGE. Censo Agropecuário (2006). Agricultura Familiar - Brasil, Grandes Regiões e Unidades da Federação.

IBGE. (2019). Em junho, IBGEprevêalta de 4,2\% na safra de gãos de 2019. https://www.ibge.gov.br.

IBGE. (2004). Instituto Brasileiro de Geografia e Estatística. Indicadores agropecuários 1996-2003. Rio de Janeiro: IBGE/ Coordenação de Agropecuária. 68.

IRGA - Instituto Riograndense do Arroz. Arroz RS - O Programa da Produtividade.

Jouany, J. P. (2007). Methods for preventing, decontaminating and minimizing the toxicity of mycotoxins in feeds. Animal Feed Science and Technology, Amsterdam, 137, 342-362.

Kakade, M. L., \& Evans, R.J. (1965). Growth inhibition of rats fed navy bean fractions. J. Agric. Food Chem., 3, 450.

Lazzari, F. A. (1997). Umidade, fungos e micotoxinas na qualidade de sementes, grãos e rações. Curitiba, Edição do autor, 134.

Lazzari, F. A., \& Lazzari, S. M. N. (2002). Colheita, recebimento, secagem e armazenamento de milho. Apucarana, ABIMILHO, 22.

Link, D., Rosseto, C. J., \& Igue, T. (1971). Resistência relativa de variedades de arroz em casca, ao ataque de Sitophilus oryzae (Linné, 1763), Sitophilus zeamais (Motschulsky,1855) e Sitotroga cerealella (Olivier, 1819) em condições de laboratório. Santa Maria: Universidade Federal de Santa Maria,70.

Lima, R. F., Souza, A. M. B., Silva, A. O., Pontes, L. R. T., \& Mota, A. V. Estudo do perfil sócio econômico dos consumidores de mel da região Nordeste Paraense: uma abordagem a partir do município de Terra Alta. In: Anais do Congresso Internacional das Ciências Agrárias, João Pessoa, 2018. Paraíba: III COINTER-PVDAGRO, 2018.

Lima, R. F., Silva, A. O., Dias, P. H. B., Silva, B. C., Guimarães, W. R., Vasconcelos, E. S., Santos, A. V. F., \& Silva, D. A. S. (2020). A produção de mandioca (manihot esculenta crantz) na agricultura familiar da região nordeste paraense: estudo a partir da comunidade de jacarequara, capanema, pará. brazilian journal of animal and environmental research, (3), 1284-1296. 10.34188/bjaerv3n3-047

Lopes, R. P., Hara, T., Silva, J. S. \& Riedel, B. (2000). Efeito da luz na qualidade (cor e bebida) de grãos de café beneficiados (Coffea arábica L.) durante a armazenagem. Revista Brasileira de Armazenamento, Viçosa, 25, 9- 17.

Lorini, I. (2002). Descrição, biologia e danos das principais pragas de grãos armazenados. In: Lorini, I., Miike, L. H., \& Scussel, V. M. (Ed.). Armazenagem de grãos. Campinas: Instituto Biogeneziz, 379-397.

Lorini, I., Beckel, H. (2002). Mecanismos de resistência das pragas de grãos armazenados. Embrapa Trigo, 6.

Lorini, I. (2015). Perdas anuais em grãos armazenados chegam a 10\% da produção nacional. Visão agrícola n¹3 2015.

Lorini, I., \& Schneider, S. Pragas de grãos armazenados: resultados de pesquisa. https://www.embrapa.br/busca-de-publicações/-/publicação/849312/pragasde-grãos-armazenados-resultados-de-pesquisa.

Marsaro Jr., A. L. (2007). Insetos-praga e seus inimigos naturais na cultura do feijão-caupi no Estado de Roraima. In: Workshop Sobre A Cultura Do FeijãoCaupi Em Roraima, 1. Boa Vista. Anais... Boa Vista: UFRR, Embrapa, 2007. CD-ROM.

Maréchal, R., Mascherpa, J. M. \& Stainier, F. (1978). Étude taxonomique d'um groupe complexe d'espèces de genres Phaseolus et Vigna (Papilionaceae) sur la base de donneés morplhologiques et polliniques, traitées par l'analyse informatique. Boissiera, Geneve, 28, 1-273. https://ci.nii.ac.jp/naid/10020031043.

Medina, C. C. (1989). A importância do armazenamento a nível de propriedade rural. Semina.10(1). 
Menezes, A. C. S. G. (2007). Importância sócio-econômica e condições de Cultivo Do Feijão-Caupi Em Roraima. In: Workshop Sobre A Cultura Do FeijãoCaupi Em Roraima, 2007, Boa Vista. Anais... Boa Vista: UFRR, Embrapa. CD-ROM. Recuperado de http://seer.sct.embrapa.br

Mishra, M. K., \& Slater, A. (2012). Recent advances in the genetic transformation of coffee. Review article. Biotechonolgy Researche International. 17.

OIC. (2012). International Coffee Organization. Aspects botanicals.

OIC. (2015). Organização Internacional de Café.

Oliveira, C., Silva, B. M. S., Sader, R. \& Morô, F. V. (2012). Armazenamento de sementes de carolina em diferentes temperaturas e embalagens. Ciência Rural, 42(1), 68-74.

Penteado, S. R. (1998). Uso de atmosfera modificada e embalagens ativas, na conservação de figo "Roxo de Valinho”. (Ficus carica L.). 1998. 100 f. Tese (Doutorado) - Escola Superior de Agricultura Luiz de Queiroz, Piracicaba.

Popinigis, F. (1977). Fisiologia da semente. Brasília, DF: Ministério da Agricultura, AGIPAN, 289.

Pontes, S. (2002). The '’latte revolucion? Regulation, markets and consumption inglobal coffee chain. Word Development, Oxford. 30(7),1099-1122.

Popinigis, F. (1985). Fisiologia da semente. (2a ed.), Agiplan, 289.

Puzzi, D. (2000). Abastecimento e armazenamento de grãos. Instituto Campineiro de Ensino Agrícola, 666.

Romeiro, A. R. (1987). Ciência e Tecnologia na Agricultura: algumas lições da história. in Cadernos de Difusão de Tecnologia, 4(1), Embrapa, Brasília. Recuperado de http://seer.sct.embrapa.br.

Rodrigues, B. R. F., Leal, J. R. S., Rodrigues, I. R. S., Santos, A. S., Silva, D. A. S., Silva, A. O., Viegas, I. J. M., Galvao, J. R., \& Frazao, D. A. C. (2020). Use of agroecological practices in the family farming of the community of our lady, belonging to the city of Capanema-pa. international journal of development research, (10), 32917-32920.

Rossignoli, P. A. (1983). Atmosfera modificada por filmes de polietileno de baixa densidade com diferentes espessuras para conservação da banana prata em condições ambientes. 81 f. Dissertação (Mestrado) - Escola Superior de Agricultura de Lavras, Lavras.

Santos, J. P. (2006). Controle de pragas durante o armazenamento de milho. Embrapa Milho e Sorgo, 20.

Santos, J. P. Paiol balaio de milho: prevenção contra caruncho e roedores. Sete Lagoas: Embrapa Milho e Sorgo, $2008 \mathrm{~b} .7$ p.

Santos, J. P. (2008). Controle de pragas durante o armazenamento de milho. In: Cruz, J. C., Karam, D., Monteiro, M. A. R., Magalhães, P. C. (Ed.). A cultura do milho. Sete Lagoas: Embrapa Milho e Sorgo, 257-302.

Santos, J. P., \& Mantovani, E. C. (1997). Perdas de grãos na cultura do milho: pré-colheita, colheita, transporte e armazenamento. Embrapa Milho e Sorgo. 40

Silva, J. S., Berbert, P. A., Rufato, S., \& Afonso, A. D. L. (2008 ${ }^{a}$ Indicadores da qualidade dos grãos. In: Silva, J. S. (Ed.). Secagem e armazenagem de produtos agrícolas. Viçosa, MG: Aprenda Fácil, 63-107.

Silva, A. O., Mera, W. Y. W. L., Santos, D. C. R., Souza, D. P., Silva, C. G. N., Raiol, L. L., Silva junior, A. M. G., Silva, D. A. S., \& Viegas, I. J. M. (2020). Estudo da produção de açaí (Euterpe oleracea Mart): aspectos econômicos e produtivos baseados nos anos de 2015 a 2017/Açaí (Euterpe oleracea Mart) production study: economic and productive aspects based on 2015-2017. Brazilian Journal of Development, (01) 1629-1641. Recuperado de DOI: $10.34117 /$ bjdv6n1-112.

Silva, A. O, Silva, A. O., Rosário, I. C. B., \& Silva, E. T. D. (2019). Extensão rural na região nordeste paraense: avaliação das principais problemáticas existentes no meio rural, Tatajuba, Viseu-Pa. In: Tayronne de Almeida Rodrigues,J Leandro Neto. (Org.). Práticas de Produção Agrícola e Conservação Ambiental. Atena Editora, 44-50.

Silva, A. O, Silva Júnior, A. M. G., Sousa, L. M., Souza, D. P., Carvalho, L. T. S., Barata, H. S., Silva, J. B., \& Silva, H. M. L. (2019) Dinâmicas de uso da terra na agricultura familiar: o caso da comunidade rural de Tatajuba, Viseu-Pará. In: Dioclea, A. S. S. (Org.). Agronomia: Elo da Cadeia Produtiva 5. Atena Editora, 5, 161-169).

Smartt, J. (1990). Grain legumes: evolution and genetic resources. Cambridge: Cambridge University Press. 333. htpp: books.google.com.br.

USDA. (2015). United States Department of Agriculture. Production arabica and robusta coffee.

Vieira, N. G., Carneiro, F. A., Sujii, P. S., Alekcevetch, J. C., Freire, L. P., Vinecky, F., Elbelt, S., \& Andrade, A. C. (2013). Different molecular mechanisms account for drought tolerance in Coffea canephora var. conilon. Tropical plant biology, 6(4), 181-190.

Villela, F. A., Peres, W. B. (2004). Coleta e beneficiamento e armazenamento. In: Ferreira, A. G., Borghetti, F. (ed). Germinação do básico ao aplicado. Artmed, 17, 265-271.

Warham, E. (1986). Comparison of packaging materiais for seed with particular reference to humid tropical environments. Seed Sciense \& Technology, Zürich,14(1), 191-211. 